\title{
Application of neural networks in CRM systems
}

\author{
Agnieszka Bojanowska ${ }^{1, *}$ \\ ${ }^{1}$ Lublin University of Technology, Faculty of Management, Department of Marketing, Nadbystrzycka 38, 20-618 Lublin, Poland
}

\begin{abstract}
The central aim of this study is to investigate how to apply artificial neural networks in Customer Relationship Management (CRM). The paper presents several business applications of neural networks in software systems designed to aid CRM, e.g. in deciding on the profitability of building a relationship with a given customer. Furthermore, a framework for a neural-network based CRM software tool is developed. Building beneficial relationships with customers is generating considerable interest among various businesses, and is often mentioned as one of the crucial objectives of enterprises, next to their key aim: to bring satisfactory profit. There is a growing tendency among businesses to invest in CRM systems, which together with an organisational culture of a company aid managing customer relationships. It is the sheer amount of gathered data as well as the need for constant updating and analysis of this breadth of information that may imply the suitability of neural networks for the application in question. Neural networks exhibit considerably higher computational capabilities than sequential calculations because the solution to a problem is obtained without the need for developing a special algorithm. In the majority of presented CRM applications neural networks constitute and are presented as a managerial decision-taking optimisation tool.
\end{abstract}

\section{Introduction}

Customer Relationship Management (CRM) is a relatively recent concept developed on the border of management and marketing in the early 1980s. Major factors that spurred the developments in the field were:

- increasing the knowledge of customers on goods and services,

- discovering the profit of maintaining lasting relationship with best customers,

- the emergence of a global competition of goods and services,

- the growing need for managing large amounts of customer data,

- the rising interest in the profits from customer behaviour data processing.

Customer loyalty is widely recognised to be one of the key components of success in virtually any business. It can be increased through effective management of customer information and this will expand the business for the organizations [3]. Lin and Su [1] showed how CRM strategies if implemented effectively can increase customer value and provide satisfaction for customers.

It may be assumed that the concept of CRM is composed of two parts: the material component, i.e. IT systems of CRM including hardware, and the non-material, abstract element, which may be understood as the philosophy of CRM. The philosophy of CRM is the customer approach of a company rooted in its organisational culture. The system, on the other hand, consists of IT tools, such as databases and proper database processing tools. In order for customer management to generate profit for the company, the two foundations of the concept, the material and the abstract, must work in unison. The key problem with CRM is that the concept has yet to be conclusively defined in economics. The understanding of CRM is frequently situational, and depends on the current needs of a company deploying the system. Certain definitions highlight the systematic facet of CRM, i.e. the software and hardware, while others simultaneously treat the system as subordinate to the philosophy of building long-term relationships with customers. The approach presented in the following paper focuses on software tools dedicated for CRM systems; specifically, it is an attempt to apply artificial neural networks to a CRM system. Therefore, throughout when referred to in this paper CRM shall stand for: a system of tools and technologies aiding customer relationship management. In addition, it will be understood as a place where all data regarding customers, partners, suppliers or any stakeholders of any connection with the company is stored. This unique combination of technology and processes enables easy access to customer history, facilitates mailing management, preparation and issuing offers, focus on most profitable customers or management of salesforce.

\section{CRM systems}

At present there is an abundance of CRM systems in Poland and abroad. Software providers offer more or less complex solutions, which may be classified into several categories: dedicated for a particular enterprise (more expensive), universal, general-purpose solutions, which must be selected by a company considering its actual needs, and open source systems or systems based on

\footnotetext{
* Corresponding author: a.bojanowska@pollub.pl
} 
popular software, e.g. MS Office. To select a proper CRM solution several aspects need to be taken into consideration, e.g.:

- What is the anticipated amount of customer data for the system to manage?

- What analyses is the software expected to carry out?

- Will the system be managed remotely or must it be centralised and company-based?

- Will the new software be compatible with systems already in use at the company (e.g. Enterprise Resource Planning, ERP)?

- Does the CRM solution provider offer employee training in both CRM system and philosophy?

- What is the budget of the company planning to implement CRM?

The type of CRM software and the shape of the whole system will depend on the way the company defines its needs; for instance, certain enterprises focus on increasing the number of loyal customers, whereas others seek to determine key customers in order to manage them.

An effective CRM system should:

- enable cloud storage of data;

- allow centralised administration of the programme;

- identify users entering and changing data, as well as all personnel with an access to the data, with regards to Personal Data Protection Act;

- enable multidimensional analysis of customer data;

- enable automation in contacts with customers;

- facilitate developing marketing campaigns, particularly the individualised ones;

- cooperate actively with social media.

CRM systems play an active role in aiding the work of the managerial board, and different departments in the company: marketing, sales, customer service, accounting and customer service; furthermore, it has an indirect impact on the work of other departments. It is therefore imperative that the system should work effectively and promote realisation of goals specified for the implemented concept of CRM. The subsequent sections of this paper show examples of implementations of neural networks contributing to the effectiveness of the system.

\section{Neural networks in business applications}

Similarly to CRM, artificial neural networks originate in 1980s, and the latter were developed side by side with the exploration of artificial intelligence. Initial studies which were critical to the developments in the field focused on building models of basic structures of the brain. A simplified operation of neural structures is shown in Fig. 1.

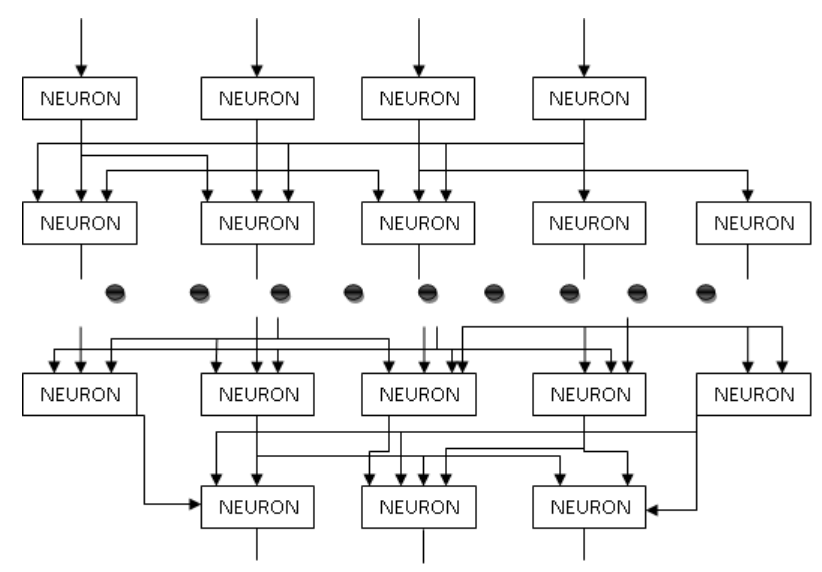

Fig. 1. Neural network [4].

Neural networks are found in a plethora of applications, such as:

- diagnostics of electronic systems,

- psychiatric examination,

- stock market forecasting,

- sales prediction,

- crude oil search,

- biological research interpretation,

- price forecasting,

- technological machine maintenance scheduling,

- scientific progress prediction,

- horse racing betting,

- production problems analysis,

- optimisation of commerce,

- raw material selection,

- employee assignment,

- industrial process management [4].

The range of applications for neural networks is notably wide, however, it mainly focuses on industrial and business processes. Such great has the effectiveness of neural networks become that the search for new potential implementations is unlikely to cease in the foreseeable future. Neural networks are frequently employed in banking to assess creditworthiness of customers, or in profitability assessment of investments. They may also be found in neuromarketing studies, where certain neurological patterns serve to build the image of future customer behaviour.

Predictive neural networks play a pivotal role in predicting events and patterns in economy. The unquestionable advantage of these networks is their capability to predict input signals based on mere observation of the training data set, without the knowledge of the nature of connections between the input and output. This feature may be successfully implemented in CRM systems, whose task is to predict future behaviour of customers based on behavioural data of usually unknown mechanisms.

What is more, CRM systems might benefit from another important feature of neural networks, the capability of networks to relate similar classes to each other. Data in software systems is often stored randomly, without a possibility of linking it. Neural networks are capable of 
automated reasoning based on training data sets, which allows managers to learn about important links and aspects without overburdening them with unnecessarily detailed information, which could appear in CRM systems without neural networks.

Data analysis enabled by neural networks involves finding connections in the input data set. This sheds new light on economic analyses, and on the source of earlier failures and therefore aids preventing them in the future. This particular feature could prove decisive in prognosis of customer leaving the company and analysis of complaints.

\section{Examples of neural network in CRM applications}

Neural networks may be assigned to different tasks and used in different aspects of CRM systems. This section elaborates on four examples of such applications, which exemplify practical aspects of neural networks in the field of CRM: predicting customer expenses according to behavioural data, assessing profitability of building customer relationships, assessing probability of customer leaving the company based on complaint data, determining key customers. These aspects are of great value to managers, demanding that the CRM system implemented in their company generates substantial profit and minimises the risk of a failed investment.

\subsection{Predicting customer expenses from behavioural data}

In the overwhelming majority of cases when asked about their company objectives, managers respond that this is profit. It is for this reason that each company is predominantly focused on customer wallet share and the possibility of predicting customer future expenses. This knowledge allows businesses to develop reliable financial plans and opens investment opportunities. It is moreover important how often the purchases are made, and what the share of customer income the purchases constitute (wallet share). Predicting customer expenses was undertaken by R. Rada, B. Ruseti, N.Baçi and M.Karçanaj in "Artificial Neural Networks for Predicting Customer Expenses" [2]. In their study the data set consisted of approximately 620 records of customers respectively with input and output. Each customer was composed of different variables such as: age, marital status, social status, personal income, family income, number of persons in family and the output variable which were the expenses per month in mobile communication. The values of variables for the ones of the two-state variable domain were expressed by 0 or 1 . After transforming them into numerical values, the next step was to normalize them. The authors used the minmax standardization method. ANN algorithm was implemented in Java programming language. After training the next process was to test the remaining 310 records of customers. The predictions were made using a numerous ANN models. After the predictions were generated, they were compared with the outcome in the testing dataset. There were several main conclusions from the study. First, main benefits of a company depend directly on the definition of the target consumer for a certain product. Seeing that traditional methods are not very effective, in this article they treated the possibility of integration of data mining techniques in business. They gave a general overview of the Artificial Neural Network in Mobile Communication. According to the received results they saw that this method was more efficient than traditional ones. The data examined were taken from a survey with about 930 records. They trained over 620 consumers and results of testing on the basis of training were very good. A comparative analysis of results from the study showed that the best network was based on the hyperbolic tangent function, which gave accurate results for $82.4 \%$ of test cases.

\subsection{Profitability of building customer relationships}

Profitability of building customer relationships is a broader issue than the previously presented one. The importance of the current problem is that both overestimation and underestimation of a customer may endanger the business and generate short- and long-term loss. It ought to be mentioned that it is not beneficial to build a relationship with every customer, as implementation of CRM in a company generates costs. In addition, companies bear costs of building relationships with each particular customer. These include both fixed and variable costs, and this is why correct estimation of benefits is critical. Such estimation frequently proves complicated owing to the fact that the idea of CRM refers to both countable/monetary benefits (wallet share) and uncountable ones (e.g. positive word of mouth about the company on the market); therefore, profitability assessment will depend on what sort of business is concerned. For the reasons presented above, neural networks may prove greatly helpful in deciding whether it is profitable to develop a relationship with a customer or not.

The example below builds on 10 factors which determine the profitability of customer relationship building in a CRM system (Table 1).

A - loyalty (weighted at 0.15 and value from 1 to 5 , where 1 is the least sought value by a company, and 5 the most)

B - solvency (weighted at 0.1 and value from 1 to 5, where 1 is the least sought value by a company, and 5 the most),

$\mathrm{C}$ - purchasing regularity (weighted at 0.1 and value from 1 to 3 , where 1 is the least sought value by a company, and 3 the most),

$\mathrm{D}$ - purchasing frequency (weighted at 0.1 and value from 1 to 3 , where 1 is the least sought value by a company, and 3 the most),

E - positive word of mouth on the market (weighted at 0.15 and value from 1 to 7 , where 1 is the least sought value by a company, and 7 the most), 
$\mathrm{F}$ - amount of a single transaction (weighted at 0.08 and value from 1 to 4 , where 1 is the least sought value by a company, and 4 the most),

$\mathrm{G}$ - openness to communication with a company (weighted at 0.12 and value from 1 to 7 , where 1 is the least sought value by a company, and 7 the most),

$\mathrm{H}$ - providing the company with information regarding the market (e.g. products of competition) (weighted at 0.09 and value from 1 to 3 , where 1 is the least sought value by a company, and 3 the most),

I - unaffected relationship after recognised complaints (weighted at 0.05 and value from 1 to 3 , where 1 is the least sought value by a company, and 3 the most),

$\mathrm{J}$ - openness to new products of a company (weighted at 0.06 and value from 1 to 4 , where 1 is the least sought value by a company, and 4 the most).

The model of neural network was based on 25 records of customers. 10 inputs were applied into the network, which were defined in the preceding list. The output represents the answer to the question: "Is the investment in the relationship with this client profitable?." The answer is two-state. However, since the network generates a vector of weighted answers, this vector was converted by the criterion function to binary decisions. The form of the criterion function depends on the decision-maker and may take the following form:

$$
\begin{aligned}
& Y_{d e c}=1 \text { for } \mathrm{y}>=y_{\text {śr }} \\
& Y_{d e c}=0 \text { for } \mathrm{y}<y_{\text {śr }}
\end{aligned}
$$

where: $Y_{\mathrm{dec}}-\mathrm{a}$ two-state decision variable;

$\mathrm{y}-\mathrm{a}$ decision value;

yśr - a value generated by the network for a customer.

The model of such architecture was used to assess the profitability of building customer relationship in accordance with the concept of CRM. The structure of the network is presented in Fig. 2.

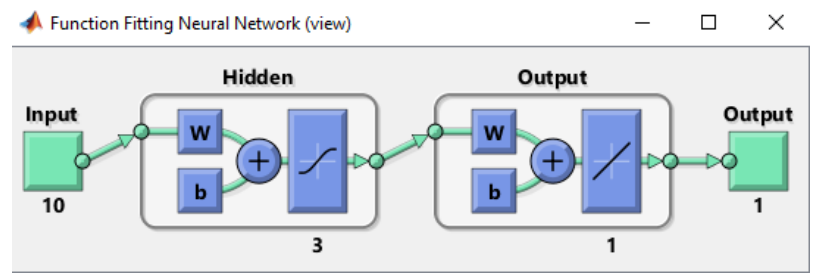

Fig. 2. Neural network used to model the process of assessing profitability of building customer relationship [Source: own work].

The model's adequacy was verified on the data obtained from 10 clients that were not included in the learning curve. The results of the simulation are shown in Table 1. Column $\mathrm{K}$ shows the result of the simulation and column $\mathrm{L}$ the calculated value based on the criteria. The simulation results show full compatibility, i.e. the network has learned to generate customer evaluation results in accordance with the adopted rating algorithm.
Table 1. Results of simulation of the cost-effectiveness analysis process of building relationships with customers using

\begin{tabular}{|c|c|c|c|c|c|c|c|c|c|c|c|c|}
\hline & \multicolumn{10}{|c|}{ Customer features } & \multirow[b]{2}{*}{$\mathbf{K}$} & \multirow[b]{2}{*}{$\mathbf{L}$} \\
\hline ID & $\mathbf{A}$ & B & $\mathbf{C}$ & D & $\mathbf{E}$ & $\mathbf{F}$ & $\mathbf{G}$ & $\mathbf{H}$ & I & $\mathbf{J}$ & & \\
\hline 1 & 5 & 3 & 3 & 2 & 5 & 3 & 6 & 1 & 2 & 3 & 1 & 1 \\
\hline 2 & 3 & 1 & 2 & 1 & 4 & 1 & 6 & 1 & 2 & 4 & 1 & 1 \\
\hline 3 & 3 & 3 & 2 & 1 & 1 & 1 & 5 & 1 & 2 & 4 & 1 & 1 \\
\hline 4 & 5 & 1 & 2 & 2 & 4 & 2 & 4 & 1 & 2 & 3 & 1 & 1 \\
\hline 5 & 2 & 3 & 1 & 1 & 6 & 3 & 6 & 1 & 3 & 4 & 1 & 1 \\
\hline 6 & 2 & 1 & 3 & 2 & 3 & 3 & 6 & 3 & 3 & 2 & 0 & 0 \\
\hline 7 & 3 & 2 & 2 & 3 & 6 & 3 & 5 & 3 & 2 & 4 & 1 & 1 \\
\hline 8 & 4 & 2 & 2 & 1 & 4 & 2 & 2 & 1 & 2 & 4 & 1 & 1 \\
\hline 9 & 1 & 2 & 2 & 2 & 2 & 3 & 2 & 2 & 1 & 1 & 0 & 0 \\
\hline 10 & 4 & 4 & 3 & 3 & 4 & 4 & 7 & 3 & 2 & 3 & 1 & 1 \\
\hline
\end{tabular}
the neural network model.

\subsection{Assessing customer behaviour from complaint data}

The lifecycle of a customer in a company is compared to the lifecycle of a product. Eventually a customer leaves the company, however, according to the principles of CRM, the company-customer relationship must be managed in such a way as to guarantee that the stage of the customer lifecycle which generates the highest profit to the company is maximally prolonged. Secondly, the company must strive to ensure that the customer leaving the company continues spreading positive word of mouth about the company on the market.

That is why it is of utmost importance to be able to predict when the customer will leave the company, and to prevent that occurrence. CRM systems implement certain information on customers, which enables making such predictions with a certain degree of probability. Algorithms for calculating the probability of such occurrences have been quite well developed, and are therefore capable of predicting whether and when the customer will leave the company. That is why, I attempted to analyse the problem in more detail, and included a conflict situation in the model. The conflict consisted in either a complaint about the service, which is not followed by any demands on the part of the customer, or a complaint about faulty goods, when the customer issues certain demands, e.g. compensation. Both types of complaint may be recognised or rejected, i.e. be resolved to the benefit of the company or to the customer's. CRM theory states that if the companycustomer relationship did not suffer after the complaint was filed, the customer should maintain a high opinion of the company and stay with the company, regardless of the decision regarding the complaint. The status of the relationship following the conflict, however, is a separate issue. The presented example takes into account the following features regarding the behaviour and condition of a customer (Table 2):

A - incidental customer (0) loyal customer (5); 
B - customer satisfaction with claim (1 happy, 0 unhappy);

C - customer satisfaction with complaint (1 happy, 0 unhappy);

$\mathrm{D}$ - number of claims;

E - number of complaints.

The network model output for the customer described with these parameters may be expressed by three values of a variable defining such a customer:

1 - customer stayed with the company but reduced expenses;

2 - customer left the company;

3 - customer stayed with the company and raised expenses;

The model was developed on 50 records of customers. and verified based on data from the remaining 20 customer, which were not included in the training data set. The neural network consisted of 5 inputs and one output, as it may be seen in Fig. 3.

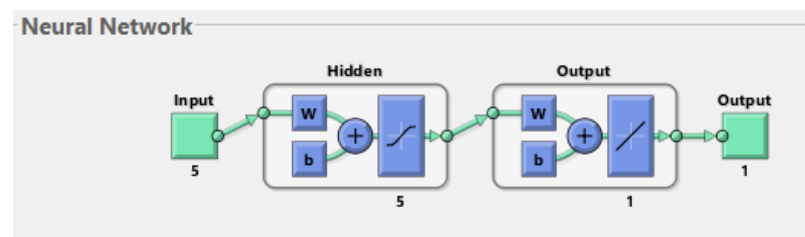

Fig. 3. Neural network used to model the process of predicting customer behaviour after complaint [Source: own work].

Table 2. Results of simulation of predicted customer behaviour based on data analysis of claims and complaints.

\begin{tabular}{|c|c|c|c|c|c|c|c|}
\hline \multirow[b]{2}{*}{ Customer ID } & \multicolumn{5}{|c|}{$\begin{array}{c}\text { Customer } \\
\text { characteristics } \\
\text { and behaviour }\end{array}$} & \multirow[t]{2}{*}{$\mathbf{F}$} & $\mathbf{G}$ \\
\hline & $\mathbf{A}$ & B & C & D & $\mathbf{E}$ & & \\
\hline 1 & 0 & 0 & 0 & 0 & 5 & 1 & 3 \\
\hline 2 & 1 & 0 & 3 & 1 & 10 & 3 & 3 \\
\hline 3 & 1 & 1 & 1 & 0 & 5 & 3 & 3 \\
\hline 4 & 1 & 0 & 10 & 1 & 7 & 2 & 2 \\
\hline 5 & 1 & 1 & 2 & 1 & 0 & 2 & 2 \\
\hline 6 & 0 & 1 & 8 & 0 & 2 & 1 & 1 \\
\hline 7 & 0 & 0 & 4 & 1 & 3 & 3 & 3 \\
\hline 8 & 1 & 0 & 7 & 1 & 5 & 3 & 3 \\
\hline 9 & 1 & 0 & 4 & 1 & 7 & 3 & 3 \\
\hline 10 & 0 & 0 & 10 & 1 & 10 & 2 & 1 \\
\hline 11 & 1 & 1 & 9 & 0 & 4 & 3 & 3 \\
\hline 12 & 0 & 1 & 7 & 1 & 0 & 3 & 3 \\
\hline 13 & 1 & 1 & 0 & 0 & 6 & 3 & 3 \\
\hline 14 & 0 & 0 & 0 & 1 & 6 & 3 & 3 \\
\hline 15 & 1 & 1 & 7 & 0 & 5 & 2 & 2 \\
\hline 16 & 0 & 1 & 7 & 1 & 2 & 1 & 1 \\
\hline 17 & 1 & 1 & 4 & 0 & 6 & 3 & 3 \\
\hline 18 & 0 & 1 & 7 & 0 & 10 & 2 & 1 \\
\hline 19 & 0 & 1 & 0 & 1 & 5 & 2 & 2 \\
\hline 20 & 1 & 0 & 1 & 1 & 10 & 1 & 1 \\
\hline
\end{tabular}

Customer behaviour prediction by the trained network showed $85 \%$ agreement with actual customer response, not included in the training data set.

The results of the simulation are shown in Table 2 . Column $\mathrm{F}$ shows the result of the simulation and column $\mathrm{G}$ the calculated value based on the criteria.

\subsection{Determining key customers}

Key customer is a consumer who will partake in the realisation of a long-term strategy of the enterprise [5]. To refer to largest purchasers as key customers is a gross simplification, and a pitfall which many modern companies are susceptible to. Maintaining a relationship with key customers is connected with significant investments, therefore in order not to expose the company to an unnecessary investment risk, key customers should be selected with due care. Different factors determine whether a customer becomes a key customer. Regardless of the type of business, certain frame must be marked for a customer to obtain the status of a key customer. In the analysed case the factors that were selected as relevant for the company were as follows (Table 3):

A- age - below 60 ;

B - marital status - married;

C - occupational status - regular employment or selfemployed;

D - personal income - over 4000 PLN;

E - wallet share - over $25 \%$;

$\mathrm{F}$ - purchase frequency - more than twice a month.

In order to build a training data set, the relationships of 50 customers with the company were analysed. The model based on the above criterion of division of customers into key (output value of model 1) and nonsatisfying (logical value 0 ). The model may be employed to determine customers of great value to a business. The knowledge contained in the neural network depends on the expert's weight weights and the degree of their fulfilment. The resulting model was verified for 10 clients whose data were not in the learning curve. The network has learned to estimate the impact of the fulfilment of specified conditions on a key client and correctly identify such a client. Fig. 4 shows a schematic representation of the designed neural network.

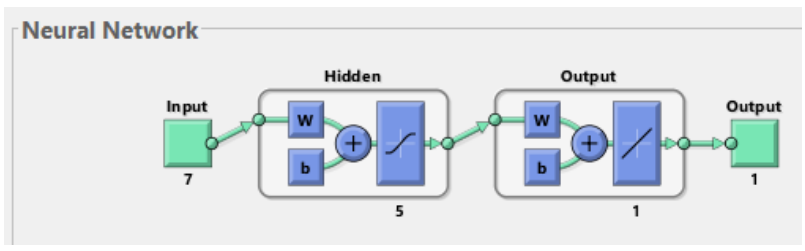

Fig. 4. Neural network used to model the process of determining key customer for a [Source: own study].

The input matrix consists of 6 attributes whose fulfilment determines the output value 1 (key customer) or 0 (customer not fulfilling the conditions). Thus created model proved to be accurate. 
Table 3. Results of simulation of the process of selecting key customers for a company using a model in a neural network.

\begin{tabular}{|r|l|l|l|l|l|l|l|l|}
\hline & \multicolumn{6}{|c|}{$\begin{array}{c}\text { Customer } \\
\text { characteristics and } \\
\text { behaviour }\end{array}$} & & \\
\cline { 1 - 6 } $\begin{array}{c}\text { Customer } \\
\text { ID }\end{array}$ & $\mathbf{A}$ & $\mathbf{B}$ & $\mathbf{C}$ & $\mathbf{D}$ & $\mathbf{E}$ & $\mathbf{H}$ & & \\
\hline $\mathbf{1}$ & 50 & 1 & 1 & 4500 & $27 \%$ & 1 & 1 & 1 \\
\hline $\mathbf{2}$ & 73 & 1 & 1 & 7190 & $22 \%$ & 4 & 0 & 0 \\
\hline $\mathbf{3}$ & 18 & 2 & 1 & 1411 & $28 \%$ & 2 & 1 & 1 \\
\hline $\mathbf{4}$ & 27 & 2 & 0 & 2252 & $47 \%$ & 2 & 0 & 0 \\
\hline $\mathbf{5}$ & 64 & 1 & 1 & 6166 & $17 \%$ & 2 & 0 & 0 \\
\hline $\mathbf{6}$ & 25 & 1 & 0 & 4419 & $37 \%$ & 4 & 1 & 1 \\
\hline $\mathbf{7}$ & 38 & 2 & 0 & 3786 & $12 \%$ & 1 & 0 & 0 \\
\hline $\mathbf{8}$ & 21 & 1 & 1 & 9405 & $34 \%$ & 2 & 1 & 1 \\
\hline $\mathbf{9}$ & 44 & 2 & 0 & 2417 & $32 \%$ & 3 & 1 & 1 \\
\hline $\mathbf{1 0}$ & 79 & 2 & 0 & 3018 & $10 \%$ & 4 & 0 & 0 \\
\hline
\end{tabular}

As shown in Table 3 for all 10 simulated cases in the network, the simulation result (col. G) was consistent with the expert estimate (col. H). These examples show that the learned neuronal principles adopted by the expert can correctly identify the key customers of the company.

\section{Summary}

As stated in the Introduction, the study of four business cases was conducted in order to show how the application of neural networks may contribute to increasing the efficiency and productiveness of CRM systems. A brief introduction into the idea of CRM and neural networks was followed by presenting several applications of the method, according to [4]. The choice of the area of application of neural networks determined that economy and business solutions were in the focal point of the study.

The examples presented in the paper indicate that it could be possible to create a neural-network dedicated software tool for customer relationship management. This may be the subject of future research in the field of neural networks and CRM.

All model presented in the article were developed in MatLab software.

\section{References}

1. Y. Lin, H. Su, TQM and BI, 14(6), 715 (2003)

2. R. Rada, B. Ruseti, N.Baçi, M.Karçanaj, J. of Edu. and Soc. Res., 6(1), (2016)

3. J. Ranjan, V. Bhatnagar, The Learning Org., 18(2), 135 (2011)

4. R. Tadeusiewicz, Sieci neuronowe (Akademicka Oficyna Wydawnicza, Warszawa, 1993)

5. S. Turek, Najważniejsi klienci czyli Key Account Management $w$ praktyce (MT Biznes, Warszawa, 2006 